\title{
The Surgeon and his Experience Remain Paramount
}

\author{
Charles N. Cornell, MD
}

Received: 22 March 2014/Accepted: 1 April 2014 /Published online: 29 April 2014

(C) Hospital for Special Surgery 2014

We are pleased to present Issue 2 of the tenth volume of HSS Journal. A variety of multidisciplinary articles are included. Among these are two articles of special interest Goodman et al. have presented their analysis of the effect that disease-modifying drugs have on the outcomes of patients undergoing total knee arthroplasty. They hypothesize that poorly controlled synovitis before surgery may lead to poor post-op function. Adequate pre-treatment with DMARD's may lead to better results. It seems likely that this may also pertain to osteoarthritic knees that manifest significant synovitis. One wonders if this synovitis may be a factor in those patients who have poorer functional results after their TKR.

The other article of particular interest is that by Merrill A. Ritter, MD and his colleagues. Please be sure to read the commentary of this article submitted by Thomas Sculco, MD. The results of this study suggest that although different technological designs of TKR prostheses may lead to measureable differences in clinical function, these differences are small and likely of limited clinical importance. However, the study also clearly points out that the four different surgeons were important to the outcomes. It appeared that each surgeon seemed to do better with the TKR that they had the most experience with and that each surgeon had his own particular favorite. My interpretation of this study is that when a surgeon gains extensive experience with a particular prosthesis, he generally learns the nuances of that design and optimizes his results. This surgical factor may be far more important than the particular design. The orthopedic market place encourages both surgeons and patients to embrace new technologies. Ritter and his colleagues with their report seem to urge caution when considering new devices. New designs may be appealing, but the new learning curve for any new technique or tool must be considered.

I hope you find this issue of the HSS Journal helpful to your practice. I encourage you to consider submitting your work to the HSS Journal for publication. We promise a rapid turnaround time as well as a fair editorial process. Accepted manuscripts are rapidly published electronically ahead of print, and all articles are cited by PubMed Central. If we judge your work to have particular interest or appeal, we will publish it with "Open Access" so that it is free to download by any reader throughout the world. We look forward to receiving your manuscripts.

\section{Disclosure}

Conflict of Interest: Charles N. Cornell, MD receives royalty payments from Exactech Corporation, outside the work.

Human/Animal Rights: This article does not contain any studies with human or animal subjects performed by any of the authors.

\section{Informed Consent: N/A}

Required Author Forms Disclosure forms provided by the authors are available with the online version of this article. 